\title{
Interactions between the tropical ISO and midlatitude low-frequency flow
}

\author{
Lin-Lin Pan · Tim Li
}

Received: 3 October 2006/Accepted: 2 May 2007/Published online: 12 June 2007

(C) Springer-Verlag 2007

\begin{abstract}
In this study, we investigate the interaction between the tropical Intraseasonal Oscillation (ISO) and midlatitude atmospheric low-frequency variability, using observational data and numerical models, with a special emphasis on the role of the synoptic eddy feedback. A statistical closure for the synoptic eddy-to-low frequency flow feedback is constructed, based on a singular value decomposition (SVD) method with observational data. Applying this statistical closure to a barotropic model and a baroclinic $2 \frac{1}{2}$-layer model, we study the role of the synoptic eddy feedback in the midlatitude response to the tropical ISO forcing. Both observational and modeling studies show that the strongest synoptic eddy forcing appears at the Pacific and Atlantic storm-track regions, and the synoptic eddy exerts a positive feedback to the midlatitude low-frequency flow induced by tropical ISO forcing. Our numerical experiments demonstrate the possible role of midlatitude disturbance forcing in the ISO initiation at the equator. The signal of the midlatitude perturbations propagates southeastward in the form of a Rossby wave package. It may reach the equator within several days under either easterly or westerly basic flow regimes. The response at the equator has observed ISO-like structure and eastward propagation characteristics.
\end{abstract}

This paper is a contribution to the AMIP-CMIP Diagnostic Sub-project on General Circulation Model Simulation of the East Asian Climate, coordinated by W.-C. Wang.

\section{L.-L. Pan · T. Li}

International Pacific Research Center,

University of Hawaii at Manoa, Honolulu, HI, USA

L.-L. Pan $(\bowtie)$

Department of Land, Air and Water Resources,

University of California, Davis, CA 95616, USA

e-mail: 1lpan@ucdavis.edu; 1pan@hawaii.edu

\section{Introduction}

Tropical intraseasonal oscillation (ISO), especially its dominant component at the equator-Madden-Julian oscillation (MJO), has been extensively studied over the past decades (Madden and Julian 1971, 1972; Wang and Rui 1990). ISO (or MJO) consists of large-scale coupled patterns in atmospheric circulation and deep convection, and is characterized by eastward propagation across the equatorial Indian and western/central Pacific oceans at a timescale of 20-70 days (Weickmann 1983; Knutson and Weickmann 1987; Kiladis and Weickmann 1992; Madden and Julian 1994; Wang and Li 1994; Hendon and Salby 1994; Zhang 2005).

The ISO (or MJO) is often explained on the basis of equatorial Kelvin wave dynamics due to its eastward movement and large amplitude at the equator. However, the slow eastward propagation at an averaged speed of $5 \mathrm{~m} / \mathrm{s}$ (e.g., Weickmann et al. 1985; Knutson et al. 1986) distinguishes the MJO from the "pure" dry and wet Kelvin waves, which propagate eastward at greater speeds of $50 \mathrm{~m} / \mathrm{s}$ and $15-17 \mathrm{~m} / \mathrm{s}$ (e.g., Wheeler and Kiladis 1999; Wheeler et al. 2000), respectively. The large-scale wind structure of MJO is often described in terms of a convectively coupled Kelvin-Rossby wave package (e.g., Wang and Li 1994). East of the convective center, the low-level easterlies and upper level westerlies resemble the equatorial Kelvin wave. To the west, low-level westerlies (upper level easterlies) and the associated pair of cyclonic (anticyclonic) gyres straddling on the both sides of the equator are the characteristics of the equatorial Rossby wave (Madden 1986; Nogues-Paegle et al. 1989). Both Kelvin and Rossby wave structures have been considered dynamically essential to the MJO (Hendon and Salby 1994; Wang and Li 1994; Zhang 2005). 
Many studies show that the influence of MJO can extend to the subtropics and midlatitudes (Liebmann and Hartmann 1984; Weickmann et al. 1985; Lau and Phillips 1986; Knutson and Weickmann 1987; Ferranti et al. 1990; Hsu 1996; Higgins and Mo 1997; Jones 2000; Bond and Vecchi 2003; Nogues-Paegle et al. 2000; Matthews 2004). Associated with enhanced (reduced) tropical convection, the upper-level divergence (convergence) is often accompanied by a subtropical upper-level convergence (divergence) counterpart. As the convective region of ISO moves eastward along the equator from the Indian Ocean to the western Pacific, the divergent circulation connecting the tropics and subtropics also moves eastward. The subseasonal wind fluctuations associated with ISO are often observed near the exit region of the Asian-Pacific jet. In particular, a north-south dipole in the streamfunction field appears over the north western Pacific in the upper troposphere when ISO convection is located in the Indian Ocean (Knutson and Weickmann 1987; Hsu 1996; Kim et al 2006). Tropical convection may also influence midlatitude low-frequency variability indirectly via zonal wind changes (Schubert and Park 1991). Frederiksen and Frederiksen (1993, 1997) found that the MJO is a coupled tropicalextratropical mode in a baroclinic model with convective parameterization. Without convective parameterization, the internal tropical mode structure disappears but the extratropical structure is largely unchanged as is the period. This implies that tropical and extratropical ISO modes may be determined by different processes/factors. There is no generally accepted view on that.

The dynamical processes responsible for the ISO-midlatitude connection have been intensively studied. The extratropical response to anomalous tropical heating is essentially that of Rossby wave propagation and dispersion (Hoskins and Karoly 1981). The barotropically and baroclinically unstable background flows can serve potentially as an energy source for midlatitude response (Simmons et al. 1983; Frederiksen 1983; Schubert 1985; Straus and Lindzen 2000). Synoptic eddy feedback, on the other hand, may also play an important role (Schubert and Park 1991). Plumb (1985) suggests that transient eddies may act as a source of stationary wave activities over the oceans. Modeling studies of the role of the transient eddies associated with the midlatitude response to the El Nino forcing by Held and Kang (1987) and Held et al. (1989) showed that the transient eddies, which are modified by changes in the stationary flow (due to the change of tropical heating), may strongly feed back to the stationary waves. This synoptic eddy feedback plays an important role in the Pacific-North American (PNA) pattern-like response in the midlatitude to the tropical forcing (Jin et al. 2006b; Pan et al. 2006).

Previous studies based on observational analyses have suggested the potential role of subtropical Rossby wave trains, midlatitude baroclinic systems, and cold surges over the South China Sea in the initiation and intensification of MJO (e.g., Lim and Chang 1981; Hsu et al. 1990; Kiladis and Weickmann 1992; Meehl et al. 1996; Compo et al. 1999; Hoskins and Yang 2000; Lin et al. 2000). However, so far not much modeling simulation has been done to clearly demonstrate the sole initiation effect by midlatitude perturbations. In this study we will explore both the impact of the tropical ISO on the midlatitude low-frequency atmospheric variability (with a particular focus on the role of the synoptic eddy feedback) and the effect of midlatitude perturbations on equatorial ISO initiation. A simple barotropic model and a $2 \frac{1}{2}$-layer baroclinic model with a statistical closure describing the synoptic eddy feedback to low-frequency flows will be constructed. The rest of the paper is organized as follows. In Sect. 2 we describe the two models to be used in this study, and in Sect. 3 we construct a statistical closure for the synoptic eddy and low-frequency flow interaction. Sections 4 and 5 present the observational and modeling results associated with the impact of tropical ISO on midlatitude circulation. In Sect. 6 we further investigate the effect of midlatitude disturbances in ISO initiation. A conclusion is given in Sect. 7.

\section{The models}

Both a barotropic model and a 21/2-layer baroclinic model with a parameterized synoptic eddy feedback to low-frequency flows are used in this paper, to explore the role of high-frequency transients (synoptic eddy) in the tropicalmidlatitude teleconnection.

\subsection{A barotropic model with synoptic eddy feedback}

The barotropic model used here is similar to that used in Pan and Jin (2005; see also Pan 2003; Jin et al. 2006a, b) except that we use a statistical closure to relate the synoptic eddy forcing to the low-frequency flow. The barotropic vorticity equation for the low-frequency variability can be written as

$$
\begin{aligned}
& \frac{\partial \Delta \bar{\psi}_{a}}{\partial t}+J\left(\bar{\psi}_{a}, \Delta \bar{\psi}_{c}+f\right)+J\left(\bar{\psi}_{c}, \Delta \bar{\psi}_{a}\right) \\
& \quad=-\left.J\left(\psi^{\prime}, \Delta \psi^{\prime}\right)\right|_{a}+\bar{F}_{\xi}
\end{aligned}
$$

where streamfunction $\psi$ is separated into three parts: a climatological basic state $\bar{\psi}_{c}$, a low-frequency anomaly component $\bar{\psi}_{a}$, and a high-frequency synoptic eddy component $\psi^{\prime}$. The $\Delta$ and $J$ are Laplacian and Jacobian operators, respectively; $f$ indicates the Coriolis parameter, and $\bar{F}_{\xi}$ represents dissipations and external forcing (e.g., f*Diver- 
gence). The dissipation terms included here are a biharmonic horizontal diffusion with the damping timescale of one day for the smallest wave, and the Newtonian damping and Rayleigh friction. The latter is represented by a linear drag that has an e-folding timescale of 10 days. The forcing is derived based on regressed $250 \mathrm{hPa}$ divergence fields. The climatological basic state is obtained by time average at $250 \mathrm{hPa}$ for the northern hemisphere cold season (November-March) between 1979 and 2002. The barotropic model is a spectral model with triangular truncation at T42. The time stepping is implicit, with a time increment of 30 minutes. Without the transient eddy forcing term $\left.\overline{J\left(\psi^{\prime}, \Delta \psi^{\prime}\right)}\right|_{a}$, Eq. (1) is reduced to a traditional linearized barotropic model. By constructing a statistical relationship between the observed transient forcing $\left.\overline{J\left(\psi^{\prime}, \Delta \psi^{\prime}\right)}\right|_{a}$ and low-frequency anomaly $\bar{\psi}_{a}$ fields, we obtained a statistical closure for the transient eddy forcing, this is, $-\left.\overline{J\left(\psi^{\prime}, \Delta \psi^{\prime}\right)}\right|_{a}=\mathbf{L}_{\mathbf{s}} \bar{\psi}_{a}$. where $\mathbf{L}_{\mathbf{s}}$ is a feedback matrix. The detailed description of this statistical closure method can be found in the next section. After this statistical closure is derived, the system is closed. Then we use this model to investigate the role of synoptic eddy feedback in the midlatitude atmospheric response to the tropical ISO forcing.

\subsection{A 21/2-layer baroclinic model}

We extend the original 21/2-layer model (Wang and $\mathrm{Li}$ 1993; Li and Wang 1994; Wang and Xie 1996) to include the synoptic eddy feedback. The governing equations for zonal wind $(u)$, meridional wind $(v)$ and temperature $(T)$ are (Wang and Li 1993):

$\frac{D u}{D t}=f v-\frac{\partial \Phi}{\partial x}+F_{u}$,

$\frac{D v}{D t}=-f u-\frac{\partial \Phi}{\partial y}+F_{v}$,

$\frac{D T}{D t}-\frac{\alpha}{C_{p}} \omega=\frac{Q}{C_{p}}+F_{T}$,

where $\Phi, Q, C_{p}, \omega$, and $\alpha$ denote geopotential height, diabatic heating, specific heat, vertical velocity, and specific volume, respectively. In the first part that investigates the midlatitude synoptic eddy feedback, a fixed heating pattern (regression based on the OLR index) is specified. In the second part that examines the effect of midlatitude perturbations on the equatorial ISO initiation, a circulationdependent heating scheme is used, in which the condensational heating rate due to deep convection is parameterized on the basis of a moisture and heat budget, following Kuo (1974). The basic-state specific humidity is specified from the observed seasonal mean climatology values. $F_{u}$, $F_{v}$, and $F_{T}$ represent both dissipation and external forcing similar to $\bar{F}_{\xi}$. The Newtonian damping and Rayleigh friction have an e-folding timescale of 15 days ( 2 days) in the free atmosphere (boundary layer), and a weak vertical diffusion with a damping timescale of 1,000 days is also included.

Similar to the barotropic model, we separate all variables into climatological mean, low-frequency (intraseasonal) anomaly, and high-frequency transient (i.e., synoptic eddy with a timescale between 2 and 8 days) components, i.e.,

$u=\bar{u}_{c}+\bar{u}_{a}+u^{\prime}$,

where subscripts " $a$ " and " $c$ " stand for the intraseasonal (or low-frequency) anomaly and climatology, respectively, and a prime indicates high-frequency variability. The linearized low-frequency anomaly equations for zonal wind $\left(\bar{u}_{a}\right)$, meridional wind $\left(\bar{v}_{a}\right)$ and temperature $\left(\bar{T}_{a}\right)$ are

$$
\begin{aligned}
\frac{\partial \bar{u}_{a}}{\partial t}+ & \bar{u}_{c} \frac{\partial \bar{u}_{a}}{\partial x}+\bar{u}_{a} \frac{\partial \bar{u}_{c}}{\partial x}+\bar{v}_{c} \frac{\partial \bar{u}_{a}}{\partial y}+\bar{v}_{a} \frac{\partial \bar{u}_{c}}{\partial y}+\left(\overline{u^{\prime} \frac{\partial u^{\prime}}{\partial x}}\right)_{a} \\
& +\left(\overline{v^{\prime} \frac{\partial u^{\prime}}{\partial y}}\right)_{a}+\bar{\omega}_{c} \frac{\partial \bar{u}_{a}}{\partial p}+\bar{\omega}_{a} \frac{\partial \bar{u}_{c}}{\partial p}+\left(\overline{\left.\omega^{\prime} \frac{\partial u^{\prime}}{\partial p}\right)_{a}}\right. \\
= & f \bar{v}_{a}-\frac{\partial \bar{\Phi}_{a}}{\partial x}+\bar{F}_{u a},
\end{aligned}
$$

$$
\begin{aligned}
\frac{\partial \bar{v}_{a}}{\partial t}+ & \bar{u}_{c} \frac{\partial \bar{v}_{a}}{\partial x}+\bar{u}_{a} \frac{\partial \bar{v}_{c}}{\partial x}+\bar{v}_{c} \frac{\partial \bar{v}_{a}}{\partial y}+\bar{v}_{a} \frac{\partial \bar{v}_{c}}{\partial y}+\left(\overline{u^{\prime} \frac{\partial v^{\prime}}{\partial x}}\right)_{a} \\
& +\left(\overline{v^{\prime} \frac{\partial v^{\prime}}{\partial y}}\right)_{a}+\bar{\omega}_{c} \frac{\partial \bar{v}_{a}}{\partial p}+\bar{\omega}_{a} \frac{\partial \bar{v}_{c}}{\partial p}+\left(\overline{\omega^{\prime} \frac{\partial v^{\prime}}{\partial p}}\right)_{a} \\
= & -f \bar{u}_{a}-\frac{\partial \bar{\Phi}_{a}}{\partial y}+\bar{F}_{v a},
\end{aligned}
$$

$$
\begin{aligned}
& \frac{\partial \bar{T}_{a}}{\partial t}+\bar{u}_{c} \frac{\partial \bar{T}_{a}}{\partial x}+\bar{u}_{a} \frac{\partial \bar{T}_{c}}{\partial x}+\bar{v}_{c} \frac{\partial \bar{T}_{a}}{\partial y}+\bar{v}_{a} \frac{\partial \bar{T}_{c}}{\partial y}-\frac{\alpha}{C_{p}} \bar{\omega}_{a} \\
& +\left(\overline{u^{\prime} \frac{\partial T^{\prime}}{\partial x}}\right)_{a}+\left(\overline{v^{\prime} \frac{\partial T^{\prime}}{\partial y}}\right)_{a}+\bar{\omega}_{c} \frac{\partial \bar{T}_{a}}{\partial p} \\
& +\bar{\omega}_{a} \frac{\partial \bar{T}_{c}}{\partial p}+\left(\overline{\omega^{\prime} \frac{\partial T^{\prime}}{\partial p}}\right)_{a}=\frac{\bar{Q}_{a}}{C_{p}}+\bar{F}_{T a}
\end{aligned}
$$

We further relate the synoptic eddy forcing terms to the low-frequency anomaly terms,

$\mathbf{A}=\mathbf{L}_{s} \mathbf{B}$,

where

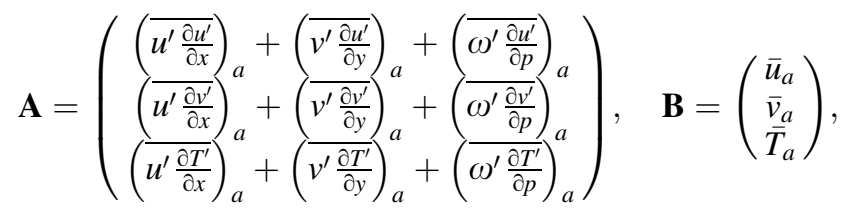


$\mathbf{L}_{s}$ is a feedback matrix, describing the interaction between the synoptic eddy and low-frequency flow. It can be statistically determined based on the observed synoptic eddy forcing terms $\mathbf{A}$ and low-frequency anomalies $\mathbf{B}$. With this statistical relationship, the $2 \frac{1}{2}$-layer model is closed. In the next section we describe in detail how this statistical closure for the synoptic eddy feedback is derived.

The baroclinic model is a grid-point model, with finitedifference schemes applied in both space and time; the time increment is $30 \mathrm{~min}$. In addition to a leapfrog timeintegration scheme, Euler and Euler-backward schemes are used every $12 \mathrm{~h}$ to reduce numerical noises. Spatial resolution in standard runs is $5^{\circ}$ longitude by $2^{\circ}$ latitude. A finer resolution of $2.5^{\circ}$ longitude by $2^{\circ}$ latitude was tested, and the results are not sensitive to the change in resolution. The climatological seasonal mean basic state is derived from the NCEP-NCAR (National Centers for Environmental Prediction-National Center for Atmospheric Research) reanalysis at 200 and $850 \mathrm{hPa}$, respectively.

\section{A statistical closure for synoptic eddy feedback}

We derived a statistical closure for synoptic eddy feedback based on NCEP-NCAR reanalysis data (Kalnay et al. 1996) by using a singular value decomposition (SVD) method.

Through the singular value decomposition (Navarra 1993; Bretherton et al. 1992) of the covariance matrix $\mathbf{C}$ of the synoptic eddy forcing anomaly $\mathbf{A}$ and the low-frequency flow anomaly $\mathbf{B}$, we have

$\mathbf{C}=\mathbf{X}^{\mathrm{A}} \Sigma\left(\mathbf{X}^{\mathrm{B}}\right)^{\mathrm{T}}$,

where $\mathbf{X}^{\mathrm{A}}$ and $\mathbf{X}^{\mathrm{B}}$ are orthonormal matrices, which give the covaring patterns of $\mathbf{A}$ and $\mathbf{B}$. The $\left(\mathbf{X}^{\mathrm{B}}\right)^{\mathrm{T}}$ denotes the transpose of $\mathbf{X}^{\mathrm{B}}$, and $\Sigma$ is a diagonal matrix of real singular values. The time series $\mathbf{Y}^{\mathrm{A}}$ and $\mathbf{Y}^{\mathrm{B}}$ corresponding to the spatial patterns $\mathbf{X}^{\mathrm{A}}$ and $\mathbf{X}^{\mathrm{B}}$ can be obtained by projecting them onto $\mathbf{A}$ and $\mathbf{B}$,

$\mathbf{Y}^{\mathrm{A}}=\left(\mathbf{X}^{\mathrm{A}}\right)^{\mathrm{T}} \mathbf{A}, \quad \mathbf{Y}^{\mathrm{B}}=\left(\mathbf{X}^{\mathrm{B}}\right)^{\mathrm{T}} \mathbf{B}$.

Conducting a linear regression between the two time series $\mathbf{Y}^{\mathrm{A}}$ and $\mathbf{Y}^{\mathrm{B}}$ for each mode $i$,

$\mathbf{Y}_{i}^{\mathrm{A}}=\alpha_{i} \mathbf{Y}_{i}^{\mathrm{B}} \quad(i=1,2, \ldots, N)$

one may relate the eddy-forcing anomaly $\mathbf{A}$ to the lowfrequency flow anomaly $\mathbf{B}$,
$\mathbf{A}=\mathbf{X}^{\mathrm{A}} \mathbf{Y}^{\mathrm{A}}=\mathbf{X}^{\mathrm{A}}\left(\begin{array}{c}\alpha_{1} \mathbf{Y}_{1}^{\mathrm{B}} \\ \alpha_{2} \mathbf{Y}_{2}^{\mathrm{B}} \\ \vdots \\ \alpha_{N} \mathbf{Y}_{N}^{\mathrm{B}}\end{array}\right)=\mathbf{X}^{\mathrm{A}}\left(\begin{array}{c}\alpha_{1} \mathbf{X}_{1}^{\mathrm{B}} \\ \alpha_{2} \mathbf{X}_{2}^{\mathrm{B}} \\ \vdots \\ \alpha_{N} \mathbf{X}_{N}^{\mathrm{B}}\end{array}\right) \mathbf{B}$,

therefore,

$\mathbf{L}_{s}=\mathbf{X}^{\mathrm{A}}\left(\begin{array}{c}\alpha_{1} \mathbf{X}_{2}^{\mathrm{B}} \\ \alpha_{2} \mathbf{X}_{2}^{\mathrm{B}} \\ \vdots \\ \alpha_{N} \mathbf{X}_{N}^{\mathrm{B}}\end{array}\right)$

Thus we get a closure for the $2 \frac{1}{2}$-layer model if $\mathbf{A}$ and $\mathbf{B}$ are defined according to Eq. (10). A similar closure can also be obtained for the barotropic model if we change the transient forcing $\mathbf{A}$ to $-\left.\overline{J\left(\psi^{\prime}, \Delta \psi^{\prime}\right)}\right|_{a}$ and the low-frequency anomaly $\mathbf{B}$ to $\bar{\psi}_{a}$, i.e., $-\left.\overline{J\left(\psi^{\prime}, \Delta \psi^{\prime}\right)}\right|_{a}=\mathbf{L}_{\mathbf{s}} \bar{\psi}_{a}$. Using the observed $-\left.\overline{J\left(\psi^{\prime}, \Delta \psi^{\prime}\right)}\right|_{a}$ and $\bar{\psi}_{a}$, one may obtain $\mathbf{L}_{\mathbf{s}}$ through the SVD analysis of the covariance matrix for the barotropic model.

\section{Observational analysis of tropical ISO influence on midlatitude low-frequency anomalies}

The main datasets used here are daily global gridded fields (zonal wind, meridional wind, and streamfunction) from the NCEP-NCAR reanalysis from 1 January 1979 to 31 December 2002. Daily averages of the National Oceanic and Atmospheric Administration (NOAA) satellite outgoing longwave radiation (OLR) for the same period are used to represent tropical convection. The OLR data are filtered at a 20-70-day band to keep the intraseasonal signal. Three OLR indices are defined at a $10^{\circ} \times 10^{\circ}$ box centered at $\left(100^{\circ} \mathrm{E}, 0^{\circ}\right),\left(120^{\circ} \mathrm{E}, 0^{\circ}\right)$, and $\left(140^{\circ} \mathrm{E}, 0^{\circ}\right)$, respectively, to represent the tropical convection associated with ISO at different locations. The streamfunction fields at $250 \mathrm{hPa}$ and $1,000 \mathrm{hPa}$ are further regressed onto these indices to reveal large-scale flow patterns associated with ISO.

Figure 1a shows the spatial pattern of the regressed streamfunction anomaly at $250 \mathrm{hPa}$ for the OLR index at $\left(100^{\circ} \mathrm{E}, 0^{\circ}\right)$ during November to March. Here the regression is calculated based on unfiltered original streamfunction daily data and the OLR index has been normalized. The regressed pattern has positive centers in the north Indian and Atlantic Oceans and over Australia, and negative centers in the south Atlantic and Indian Oceans. A marked north-south dipole structure appears in the north Pacific, consistent with previous results (e.g., Knutson and Weickmann 1987; Hsu 1996; Kim et al. 2006). 

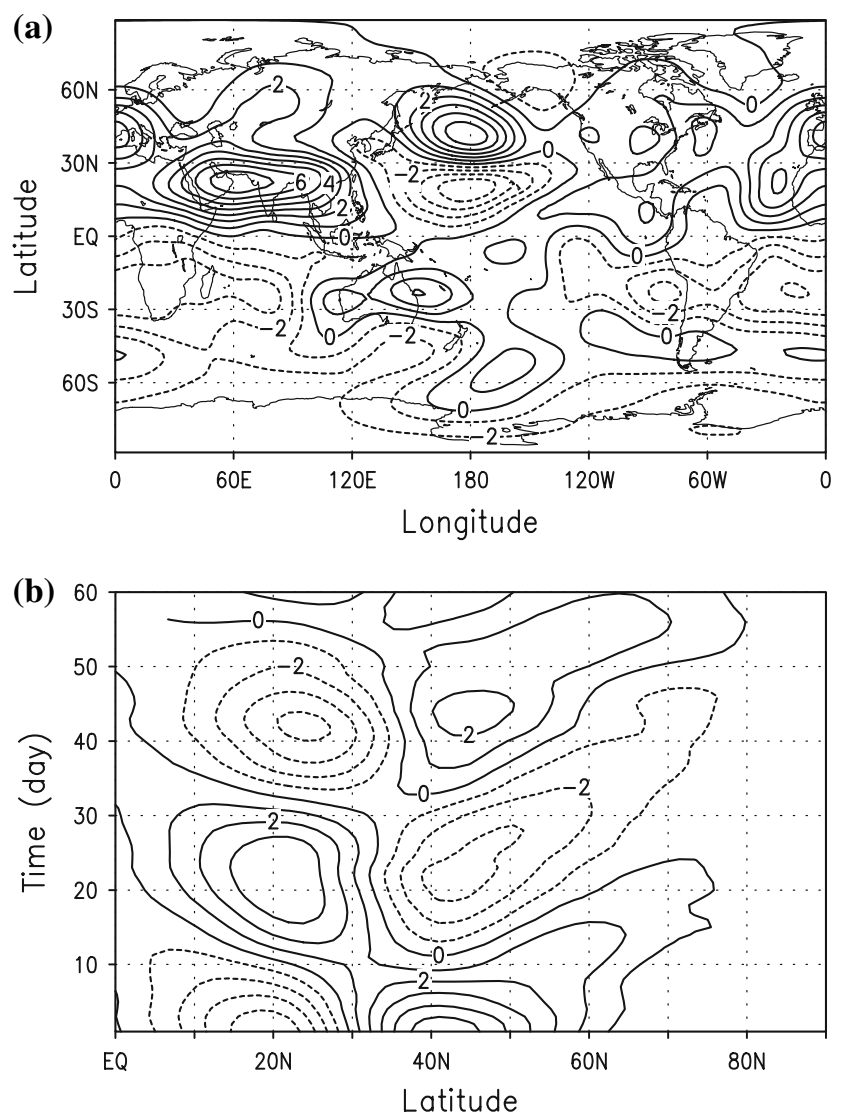

Fig. 1 a Spatial pattern and $\mathbf{b}$ time-latitude cross section at $180^{\circ}$ longitude of the $250 \mathrm{hPa}$ streamfunction anomalies regressed on the OLR index centered at $\left(100^{\circ} \mathrm{E}, 0^{\circ}\right)$ during the cold season (November-March). The contour interval is $10^{6} \mathrm{~m}^{2} \mathrm{~s}^{-1}$. The vertical axis in $\mathbf{b}$ represents the leading time (unit: day) by which the OLR index leads the streamfunction field

The temporal variation of this dipole can be clearly seen from a lag regression analysis shown in Fig. 1b. It has an oscillation period of 40 days. The result implies that the forcing associated with tropical ISO heating may produce significant atmospheric low-frequency variability in midlatitudes on the intraseasonal timescale. The variation of the dipole can be further seen from a time-longitude cross section along $20^{\circ} \mathrm{N}$ and $45^{\circ} \mathrm{N}$ (Fig. 2), corresponding to its south and north centers. Along $20^{\circ} \mathrm{N}$, the eastward propagation of the streamfunction signal is clearly evident (Fig. 2a), closely following the eastward propagation of equatorial convection from the Indian Ocean to the western Pacific. At $45^{\circ} \mathrm{N}$, the eastward propagation is only evident between $180^{\circ}$ and $60^{\circ} \mathrm{W}$, while it is unclear over other longitudes.

Figure 3 illustrates the regressed streamfunction pattern at $1,000 \mathrm{hPa}$. Compared to the upper tropospheric field (Fig. 1a), the low-level streamfunction has a monopole structure in the north Pacific, with its center located at
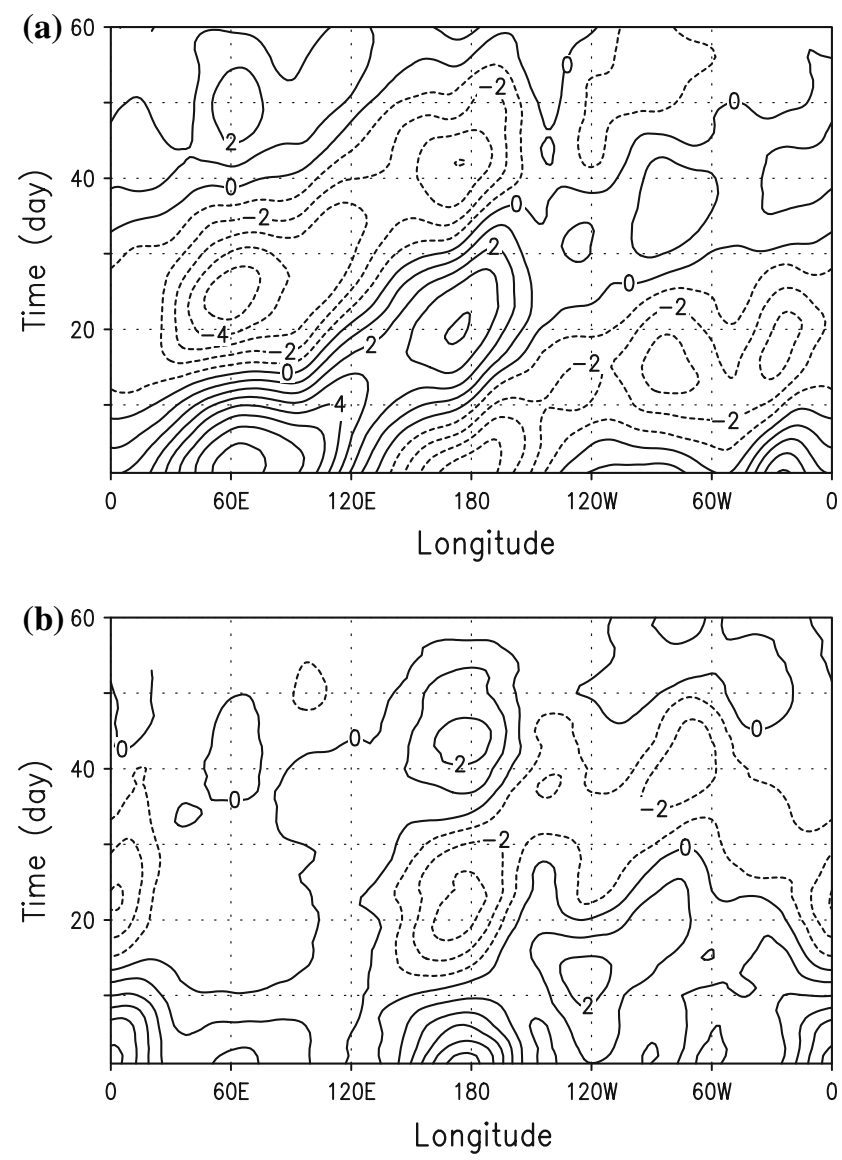

Fig. 2 As in Fig. 1b except for the time-longitude cross section at a $20^{\circ} \mathrm{N}$ and $\mathbf{b} 45^{\circ} \mathrm{N}$

$\left(180^{\circ}, 40^{\circ} \mathrm{N}\right)$. The vertical structure of the regressed rotational flow in general exhibits a baroclinic structure in the tropics $\left(30^{\circ} \mathrm{S}\right.$ to $\left.30^{\circ} \mathrm{N}\right)$. In the midlatitude it exhibits an equivalent barotropic structure. The time-latitude cross section at $180^{\circ}$ (Fig. 3b) shows a dominant oscillative period of around 40 days, consistent with the results at $250 \mathrm{hPa}$. The dominant feature for the time-longitude cross section at $1,000 \mathrm{hPa}$ is similar to that at $250 \mathrm{hPa}$.

The midlatitude flow patterns change accordingly when the forcing associated with tropical ISO moves eastward. This can be inferred from the regressed patterns associated with the OLR indices at $\left(120^{\circ} \mathrm{E}, 0^{\circ}\right)$ and $\left(140^{\circ} \mathrm{E}, 0^{\circ}\right)$ (not shown). In the tropical region, the dominant pattern does not change much except that the positive and negative centers shift eastward following the equatorial convection center (see also Fig. 2a, similar results were also obtained by Frederiksen 2002), and it still has a baroclinic structure in the vertical. In the midlatitude, there are wave train patterns, and their vertical structure remains equivalent barotropic. 

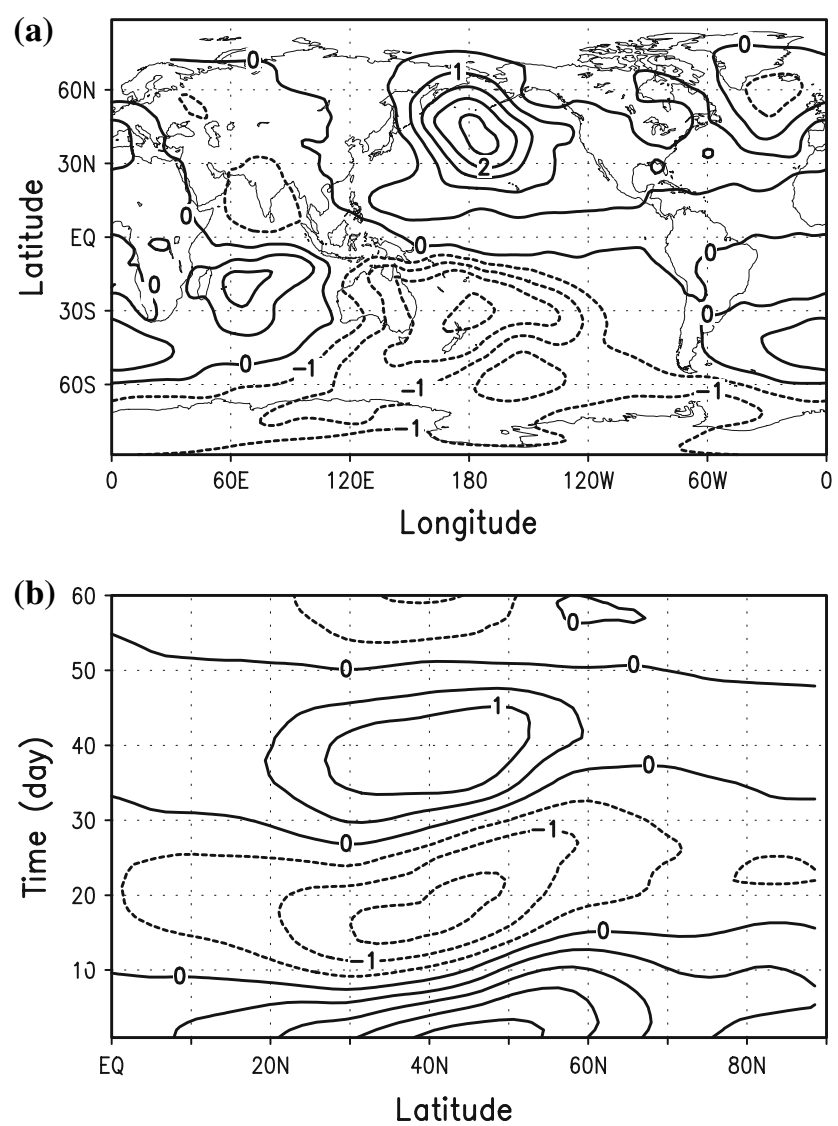

Fig. 3 As in Fig. 1 except for $1,000 \mathrm{hPa}$

\section{Role of synoptic eddy feedback in the midlatitude response to the tropical ISO}

In this section, we investigate the role of synoptic eddy feedback in the midlatitude atmospheric response to the tropical ISO forcing in both the barotropic and baroclinic models.

\subsection{Barotropic model results}

The extratropical response to anomalous tropical heating is often explained in terms of Rossby wave propagation and dispersion (Hoskins and Karoly 1981). Here using a barotropic model with the synoptic eddy and low-frequency flow interaction, we investigate the role of synoptic eddy feedback in the response of midlatitude low-frequency flows to the forcing associated with tropical ISO heating. In the following, we first validate the statistical closure for the synoptic eddy feedback in the barotropic model $-\left.\overline{J\left(\psi^{\prime}, \Delta \psi^{\prime}\right)}\right|_{a}=\mathbf{L}_{\mathbf{s}} \bar{\psi}_{a}$. and then investigate the difference in the response fields with and without the synoptic eddy feedback.

Figure 4 illustrates the model simulated eddy forcing $\left[\Delta^{-1}\left(\mathbf{L}_{\mathbf{s}} \bar{\psi}_{a}\right)\right]$ and observed eddy forcing $\left[-\left.\Delta^{-1} \overline{J\left(\psi^{\prime}, \Delta \psi^{\prime}\right)}\right|_{a}\right]$
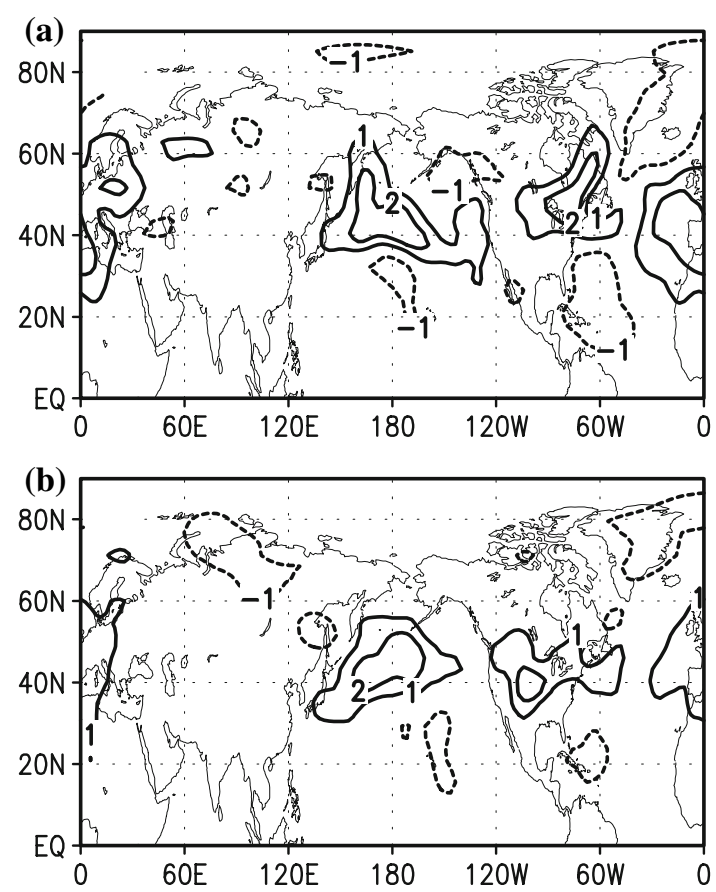

Fig. 4 Eddy forcing of the streamfunction anomaly regressed on the OLR index centered at $\left(100^{\circ} \mathrm{E}, 0^{\circ}\right)$, calculated based on a statistical closure (a) and from the observations (b). The contour interval is $1 \mathrm{~m}^{2} \mathrm{~s}^{-2}$

regressed on the OLR index at $\left(100^{\circ} \mathrm{E}, 0^{\circ}\right)$. The observed results are well reproduced by the statistical closure and the pattern correlation between observed eddy forcing and model simulated one is around 0.8. The eddy forcing mainly is located at midlatitude storm track regions, and it has a positive center around $40^{\circ} \mathrm{N}$ and a negative center to its south in the Pacific, consistent with the dipole structure in the streamfunction field (Fig. 1a). The positive correlation between the synoptic eddy forcing and low-frequency flow in the region implies that there is a positive feedback between them, which can be further confirmed by subsequent numerical experiments. Similar results are obtained for the OLR indices centered at $\left(120^{\circ} \mathrm{E}, 0^{\circ}\right)$ and $\left(140^{\circ} \mathrm{E}, 0^{\circ}\right)$ (not shown).

Next we examine the midlatitude response to tropical ISO forcing at $\left(100^{\circ} \mathrm{E}, 0^{\circ}\right),\left(120^{\circ} \mathrm{E}, 0^{\circ}\right)$ and $\left(140^{\circ} \mathrm{E}, 0^{\circ}\right)$ in the barotropic model. The forcing patterns are obtained according to the OLR patterns (not shown) regressed on the OLR indices centered at $\left(100^{\circ} \mathrm{E}, 0^{\circ}\right),\left(120^{\circ} \mathrm{E}, 0^{\circ}\right)$, and $\left(140^{\circ} \mathrm{E}, 0^{\circ}\right)$, and are confined mostly in the equatorial region $\left(15^{\circ} \mathrm{S}-15^{\circ} \mathrm{N}\right)$ (Fig. 5). The magnitude of forcing is determined by regressed $250 \mathrm{mb}$ divergence field (which has an amplitude around $5 \times 10^{-6} \mathrm{~s}^{-1}$ ). The Rossby wave source used here is just $f^{*}$ Divergence. Our focus is on the difference in the response fields between cases with and without the synoptic eddy feedback. Figure 6 shows the observed and the model simulated response fields (The 


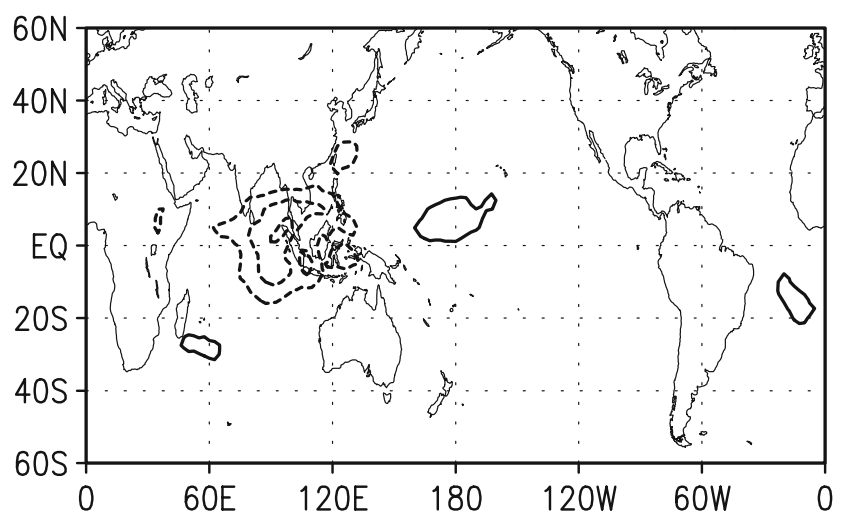

Fig. 5 Regressed pattern of OLR anomalies on the OLR index centered at $\left(100^{\circ} \mathrm{E}, 0^{\circ}\right)$. The contour interval is $6 \mathrm{~W} \mathrm{~m}^{-2}$

observed field is the same as that in Fig. 1a except that only the northern hemispheric portion is plotted here.) Comparing the results with and without the eddy feedback (Fig. 6b vs. Fig. 6c), it is clear that the response is significantly enhanced when the synoptic eddy feedback is included, implying a positive feedback between the synoptic transients and low-frequency flows in the midlatitudes. The difference field in Fig. $6 \mathrm{~d}$ shows that two maximum centers are located along the Pacific and Atlantic storm tracks.

The north-south dipole structure in the north Pacific does exist in both simulations with and without the synoptic eddy feedback. However, the strength is weaker than that of the observed when the synoptic eddy feedback is not included. To illustrate the role of the zonally asymmetric mean flow in the generation of the north-south dipole, we conducted an additional experiment in which we deliber- ately suppress the zonally asymmetric part of the climatological mean state (i.e., stationary waves) in the model. Figure 7 shows the model simulation results in this case. Without the stationary waves in the basic flow, the model failed to reproduce the observed strength of the response, as clearly shown in the difference field (Fig. 7b). This illustrates the important role of the stationary wave-lowfrequency flow interaction in the formation of the northsouth dipole structure. Consistent with previous studies by Simmons et al. (1983) and others, who pointed out the importance of the zonally asymmetric basic flow in the midlatitude response to tropical heating, here we demonstrate that both the stationary waves and transient eddies are crucial for the tropical-midlatitude teleconnection.

When the ISO forcing shifts to $\left(120^{\circ} \mathrm{E}, 0^{\circ}\right)$ or $\left(140^{\circ} \mathrm{E}\right.$, $0^{\circ}$ ), the model simulates a weaker midlatitude response, in agreement with the observations. The positive synoptic eddy feedback still exists except the strength of the feedback decreases correspondingly.

To examine the sensitivity of the model solution to nonsteady forcing, we conducted a sensitivity experiment in which we allow the ISO forcing to propagate slowly eastward along the equator. The dominant feature of the response filed is similar to that of the steady forcing except the magnitude is slightly smaller comparing with the steady response (not shown).

\subsection{Results from the $2 \frac{1}{2}$-layer model}

We further investigate the role of the synoptic eddy feedback in the midlatitude response to tropical ISO heating by using a $2 \frac{1}{2} 2$-layer model. Similar to what we did in the barotropic model, we first validate the statistical closure for
Fig. 6 Streamfunction anomaly patterns in association with the ISO forcing centered at $\left(100^{\circ} \mathrm{E}\right.$, $0^{\circ}$ ): a observational results, b barotropic model simulations without the synoptic eddy feedback, c barotropic model simulations with the synoptic eddy feedback, and d difference between the cases with and without the synoptic eddy feedback. The contour interval is $2 \times 10^{6} \mathrm{~m}^{2} \mathrm{~s}^{-1}$ for $\mathbf{a}, \mathbf{b}$ and $\mathbf{c}$, and $10^{6} \mathrm{~m}^{2} \mathrm{~s}^{-1}$ for $\mathbf{d}$
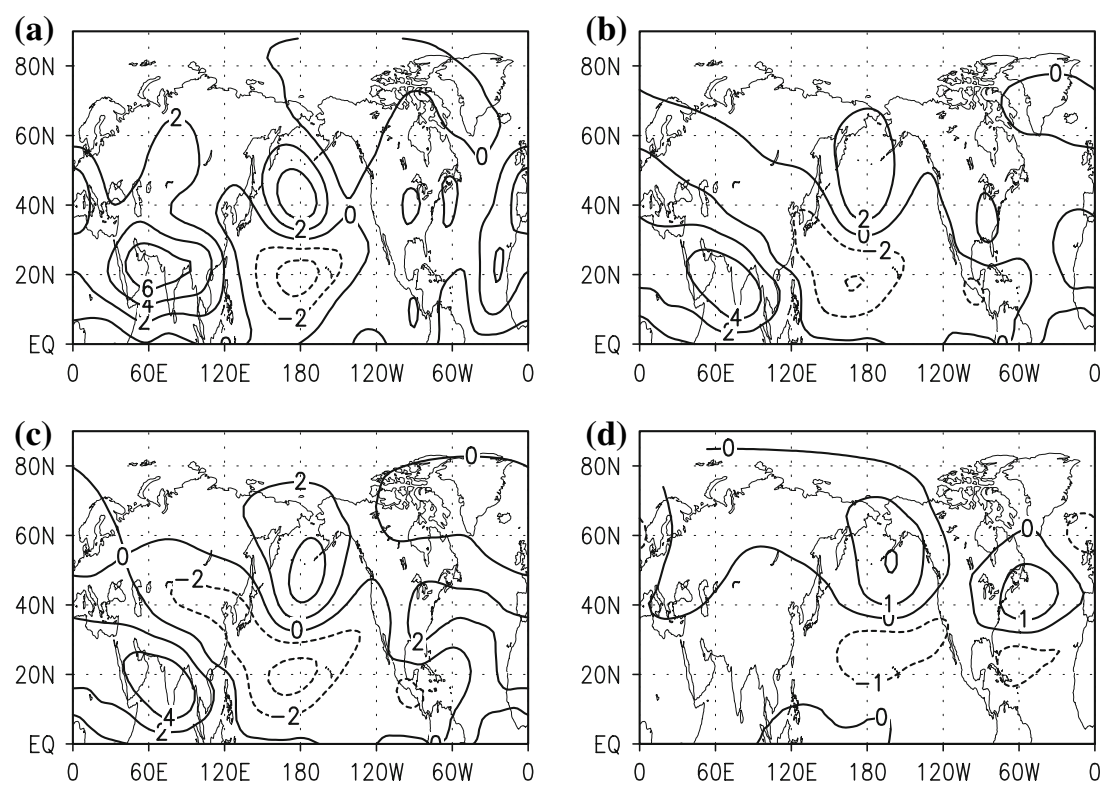

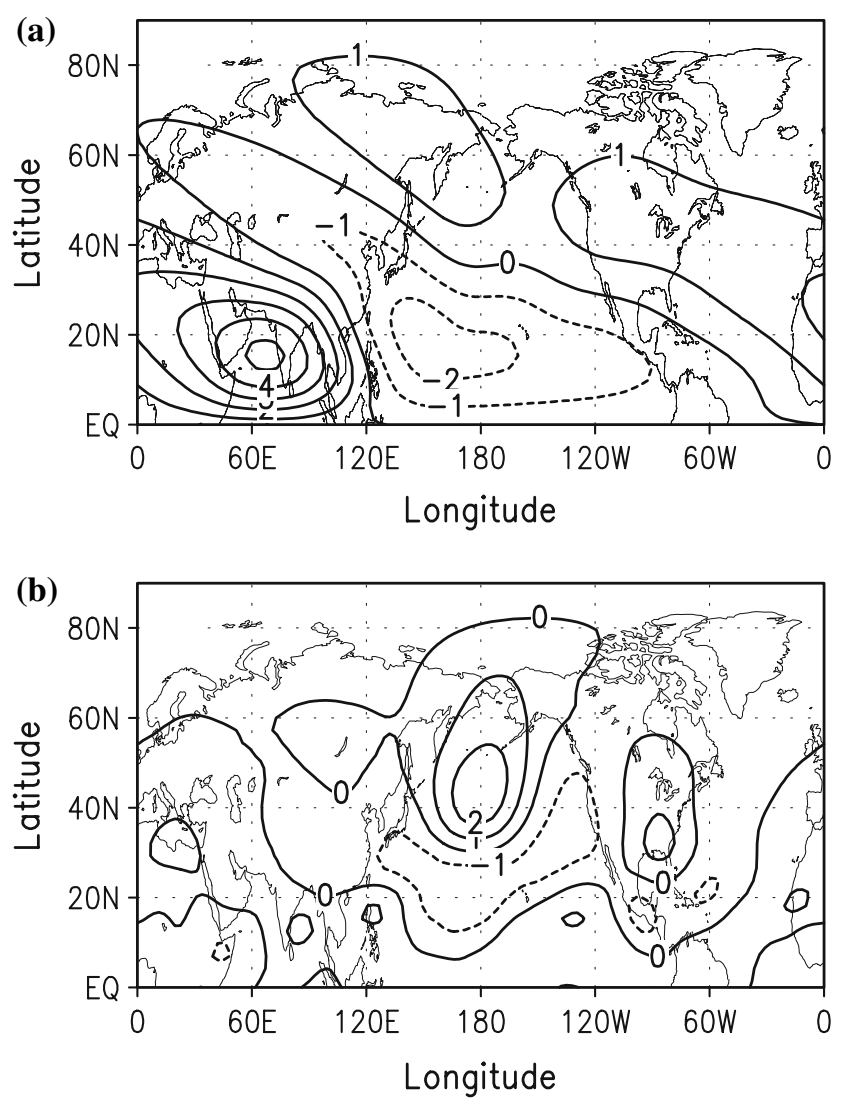

Fig. 7 a Streamfunction anomaly patterns associated with the ISOlike forcing centered at $\left(100^{\circ} \mathrm{E}, 0^{\circ}\right)$ in a barotropic model under the zonal symmetric basic state (i.e., without the stationary wave), and $\mathbf{b}$ difference of the streamfunction fields between the cases with and without the stationary wave in the basic state. The contour interval is $10^{6} \mathrm{~m}^{2} \mathrm{~s}^{-1}$

the synoptic eddy feedback in the 21/2-layer model, and then investigate the difference in the response field in cases with and without the synoptic eddy feedback.

Figure 8 compares the observed and simulated eddy forcing terms in the zonal wind equation, regressed on the OLR index centered at $\left(100^{\circ} \mathrm{E}, 0^{\circ}\right)$. The correlation between the observed and simulated patterns is around 0.75 , indicating that the statistical closure is valid. Similar to the barotropic model results, the eddy forcing mainly locates at the Pacific and Atlantic storm track regions and it positively feeds back to the low-frequency flow. The forcing field has an equivalent barotropic structure in the middle and high latitudes (not shown). Similar results are obtained for the forcing centered at $\left(120^{\circ} \mathrm{E}, 0^{\circ}\right)$ and $\left(140^{\circ} \mathrm{E}, 0^{\circ}\right)$. Therefore, the observed eddy forcing effect is well represented by the statistical closure.

After the validation of the statistical closure for the synoptic eddy feedback, we further investigate the role of the feedback in the midlatitude response to tropical forcing in the $2 \frac{1}{2}$-layer model. Similar to the previous barotropic
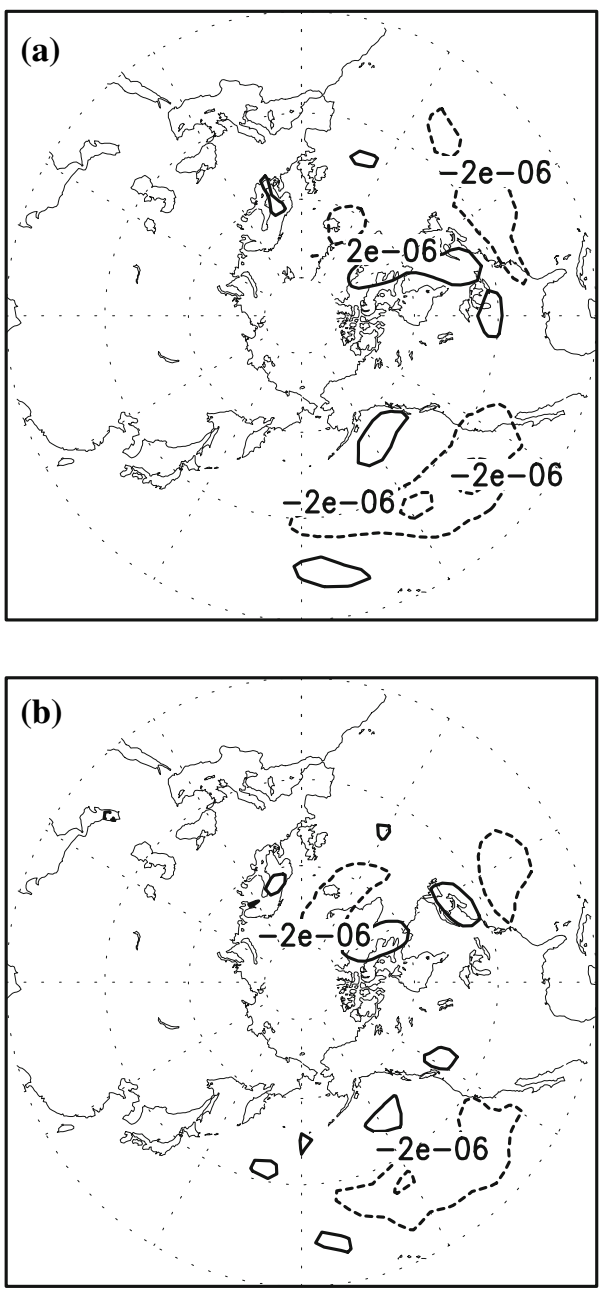

Fig. 8 As in Fig. 4 except for the zonal wind anomaly at $200 \mathrm{hPa}$ in the $2 \frac{1}{2}$-layer model. The contour interval is $2 \times 10^{-6} \mathrm{~m} \mathrm{~s}^{-2}$ and the zero line is omitted

study, we put the tropical ISO forcing at $\left(100^{\circ} \mathrm{E}, 0^{\circ}\right)$, $\left(120^{\circ} \mathrm{E}, 0^{\circ}\right)$, and $\left(140^{\circ} \mathrm{E}, 0^{\circ}\right)$, respectively, and investigate the difference in the response field between cases with and without the synoptic eddy forcing. The horizontal pattern of the forcing (heating) is based on the regressed OLR pattern while its vertical profile has a maximum in the middle troposphere. Since the model is linear, changing in magnitude of the forcing field will linearly change the response field. Figure 9 presents a comparison between the observational result (Fig. 9a) and the model simulations (Fig. 9b-c) to the ISO forcing centered at $\left(100^{\circ} \mathrm{E}, 0^{\circ}\right)$. The observational result is obtained by regressing the zonal wind field onto the OLR index centered at $\left(100^{\circ} \mathrm{E}, 0^{\circ}\right)$. Figure $9 \mathrm{~b}$ and $\mathrm{c}$ shows simulations with and without the eddy feedback, while their difference is presented in Fig. 9d. Similar to the barotropic model results, the difference mainly appears in the Pacific and Atlantic storm track regions. The response field is enhanced when the 
Fig. 9 As in Fig. 6 except for the zonal wind anomaly at $200 \mathrm{hPa}$ in the $2 \frac{1}{2}$-layer model. The contour interval is $1 \mathrm{~m} \mathrm{~s}^{-1}$ for $\mathbf{a}, \mathbf{b}$ and $\mathbf{c}$, and $0.5 \mathrm{~m} \mathrm{~s}^{-1}$ for d
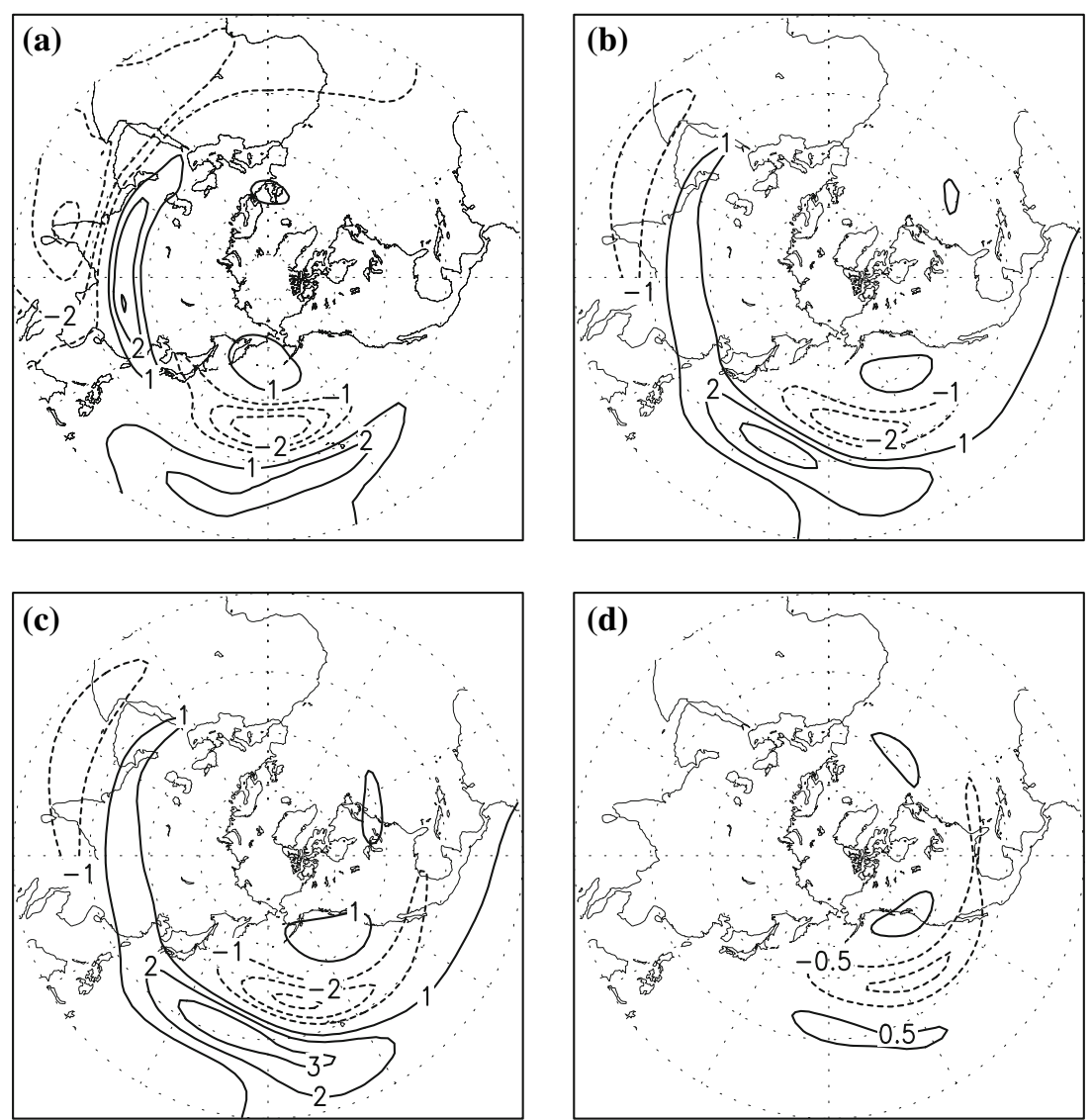

synoptic eddy feedback is included, which again implies a positive feedback between the synoptic eddy and the lowfrequency flow anomaly. Similar experiments are conducted for the forcing centered at $\left(120^{\circ} \mathrm{E}, 0^{\circ}\right)$ and $\left(140^{\circ}\right.$, $\left.0^{\circ}\right)$ and the results are in general similar. A sensitivity experiment with the specification of a zonal symmetric mean flow verifies the effect of the stationary waves in midlatitude response. By converting the streamfunction field (Fig. 6) to the zonal wind field (not shown), we can see that the barotropic and baroclinic model responses are consistent. Thus both the barotropic model and the $2 \frac{1}{2}$ layer model experiments demonstrate the role of the synoptic eddy feedback and the stationary waves in the midlatitude response to the tropical ISO forcing.

\section{ISO initiation by midlatitude disturbances}

While the tropical ISO may force a low-frequency atmospheric response in the midlatitude, the disturbances in the midlatitude, on the other hand, may initiate ISO convection at the equator, possibly through the southward propagation of subtropical Rossby wave trains (e.g., Lim and Chang 1981; Hsu et al. 1990; Compo et al. 1999; Lin et al. 2000). In this section we intend to simulate and investigate this subtropical triggering process in the 21/2-layer model.
Before conducting the model simulation, we investigate the observed relationship between the southward propagation of extratropical disturbances and the equatorial ISO convection, as revealed from the composite analysis based on daily streamfunction anomalies. Using the OLR index centered at $\left(0^{\circ}, 100^{\circ} \mathrm{E}\right)$ defined in the paper, we get the composite of the streamfunction anomalies when the OLR index is lower than one standard deviation and the box-averaged $\left(10^{\circ} \times 10^{\circ}\right)$ streamfunction anomaly centered at $\left(45^{\circ} \mathrm{N}, 20^{\circ} \mathrm{E}\right)$ is also lower than one standard

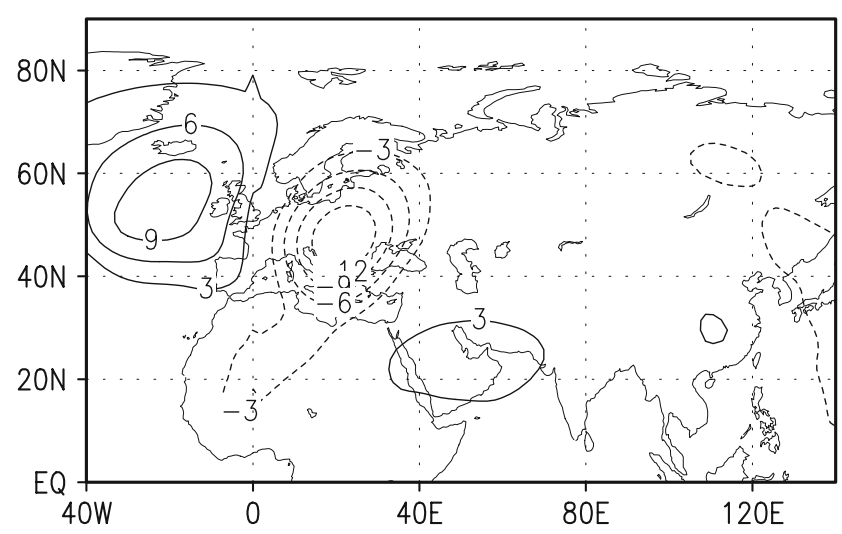

Fig. 10 Composite of streamfunction anomaly associated with convection in the Indian Ocean. The contour interval is $3 \times 10^{6} \mathrm{~m}^{2}$ $\mathrm{s}^{-1}$ 
deviation (Fig. 10). The streamfunction field is obtained from NCEP-NCAR reanalysis and the data period is from 1979 to 2002 . Figure 10 illustrates clear equatorward wave propagation characteristics.

Next we examine the influence of extratropical disturbances on equatorial ISO initiation in the $2 \frac{1}{2} 2$-layer model. A January monthly mean climatology averaged between 1979 and 2002 is specified as the model basic state. Initially, a midlatitude vorticity perturbation is introduced, with a center located at $\left(20^{\circ} \mathrm{E}, 45^{\circ} \mathrm{N}\right)$. We integrate the model forward to examine how this perturbation evolves with time and whether or not it can initiate the tropical ISO. Figure 11 shows the evolution of simulated zonal wind anomalies at $850 \mathrm{hPa}$. As time advances, the midlatitude disturbance propagates eastward and equatorward in both the lower level (Fig. 11a-d) and the upper troposphere (Fig. 12a-d). Greater signals appear to the east of the initial perturbation, owing to the effect of the mean flow. An ISOlike pattern appears in the low-level zonal wind field on the equator at $t=$ day 4 (Fig. 11e), when a coupled KelvinRossby wave structure is more evident in the upper troposphere (Fig. 12e). The vertical structure of the equatorial response at day 4 appears to be a baroclinic structure with the low-level convergence and upper-level divergence around $60^{\circ} \mathrm{E}$, coinciding well with strong mid-tropospheric ascending motion and positive rainfall anomalies. The equatorial wave perturbations grow slowly with time while propagating eastward along the equator, resembling a typical ISO event. The enhanced equatorial convection may further excite a poleward propagation of Rossby wave trains in the upper troposphere, as seen in Fig. 12f.

The ISO initiation on the equator may be further revealed by the time-longitude cross section of the zonal wind at the equator (Fig. 13). During the initiation stage, the lower-level winds grow at a much faster rate than their upper-level counterparts. For example, the low-level easterly is enhanced from -0.2 to $-1 \mathrm{~m} \mathrm{~s}^{-1}$ during day $2-6$, while the upper-level westerly increases only $0.2 \mathrm{~m} \mathrm{~s}^{-1}$. The ISO-like signal, once initiated, propagates eastward along the equator, and completes one cycle at a period of about 40 days.

It is noted that the midlatitude triggering process is associated with the southeastward Rossby wave energy dispersion. This can be seen from a time-longitude cross section along $45^{\circ} \mathrm{N}$ and a time-latitude cross section at $25^{\circ} \mathrm{E}$ of perturbation kinetic energy $\left[\left(u^{\prime 2}+v^{\prime 2}\right) / 2\right]$ (Fig. 14). Figure 14 shows that during the initial four days there is clear southward and eastward energy propagation at 850 and $200 \mathrm{hPa}$. Both the upper- and lower-level energy propagations show that the signal can reach the equator within several days. The propagation speed is about $10^{\circ}$ latitude per day, within the range of observed Rossby wave southward propagation speeds (Compo et al. 1999).

To test the sensitivity of the equatorial ISO response to the longitude location of the midlatitude disturbance, we shift the initial disturbance from $\left(20^{\circ} \mathrm{E}, 45^{\circ} \mathrm{N}\right)$ to $\left(180^{\circ}\right.$, $45^{\circ} \mathrm{N}$ ) (Fig. 15). While an equatorial ISO can still be initiated, the amplitude of the equatorial response appears
Fig. 11 Evolution of the model zonal wind anomalies at $850 \mathrm{hPa}$ at $\mathbf{a} t=$ day $0, \mathbf{b} t=$ day $1, \mathbf{c} \mathrm{t}=$ day $2, \mathbf{d} t=$ day $3, \mathbf{e} t=$ day 4 , and $\mathbf{f} t=$ day 6 . An initial disturbance is located at $\left(20^{\circ} \mathrm{E}\right.$, $45^{\circ} \mathrm{N}$ ). The contour interval is 1 $\mathrm{m} \mathrm{s}^{-1}$ for $\mathbf{a}$ and $0.1 \mathrm{~m} \mathrm{~s}^{-1}$ for $\mathbf{b}$, $\mathbf{c}, \mathbf{d}, \mathbf{e}$, and $\mathbf{f}$
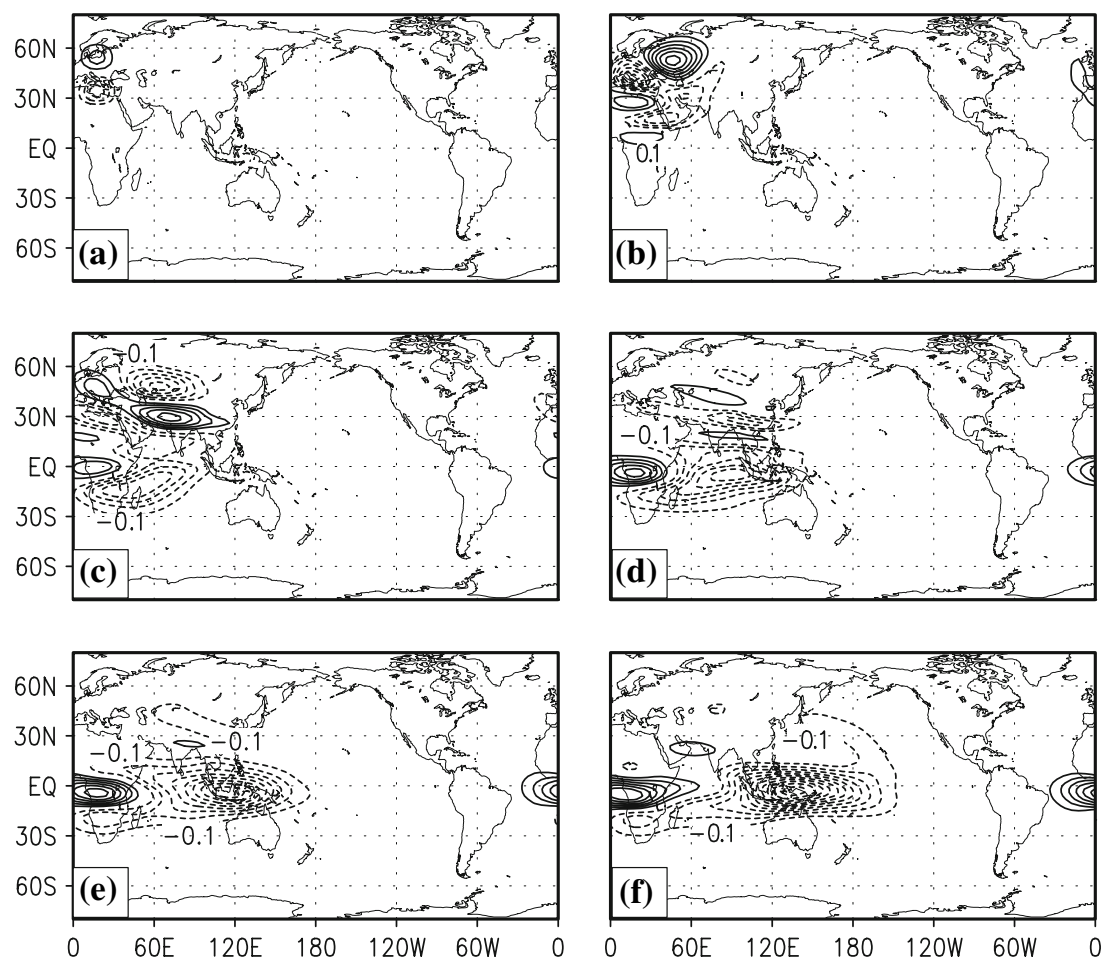
Fig. 12 As in Fig. 11 except for the zonal wind field at $200 \mathrm{hPa}$. The contour interval is $1 \mathrm{~m} \mathrm{~s}^{-1}$ for $\mathbf{a}$ and $0.2 \mathrm{~m} \mathrm{~s}^{-1}$ for $\mathbf{b}, \mathbf{c}, \mathbf{d}, \mathbf{e}$, and $\mathbf{f}$
Fig. 13 Time-longitude cross section of the zonal wind field at the equator at a lower level and b upper level. The contour interval is $0.2 \mathrm{~m} \mathrm{~s}^{-1}$
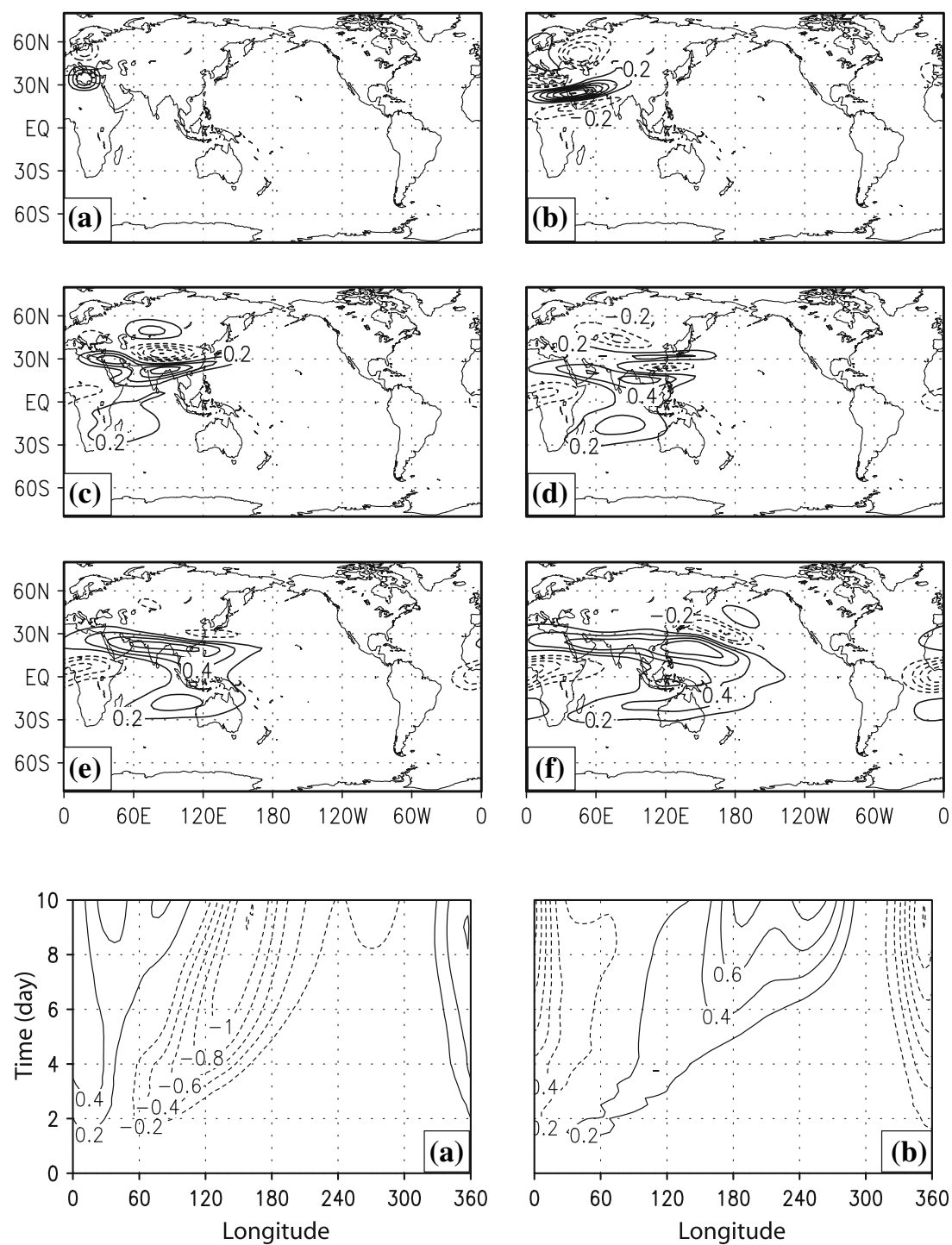

weaker and the initiation location is shifted further to the east compared to the previous case. Given that the basicstate upper-level zonal wind in the tropics is easterly (westerly) to the west (east) of around $180^{\circ}$, the experiments above demonstrate that the midlatitude wave perturbation can penetrate into the tropics and initiate an ISO under both the easterly and westerly flow regimes.

To further examine the sensitivity of the equatorial response to upper or lower-level perturbations, we conducted two parallel experiments in which an initial disturbance is placed only at the lower or upper level. The sensitivity experiments show that the equatorial response is not sensitive to the initial perturbation positions. An initial upper(or lower-) tropospheric perturbation may quickly excite a lower- (or upper-) level counterpart during a short adjustment period (within 1-2 days), and as a result, the southeastward Rossby wave propagation feature remains similar (not shown).
The effect of the zonally asymmetric mean flow (i.e., stationary waves) in the southeastward Rossby wave propagation is examined by conducting an additional experiment in which we specify a zonal symmetric basic state. Figure 16 shows the model simulation at $t=$ day 6 . Comparing it to Fig. 11f, the equatorial wind response is slightly weaker, and appears more symmetric about the equator. A further sensitivity experiment points out that the condensational heating is a primary energy source for the maintenance and growth of the ISO; without this process, no ISO-like response can be excited at the equator even though there is southward energy propagation from midlatitudes.

\section{Conclusion}

In this study, the interaction between tropical ISO and midlatitude low-frequency flow is investigated with focus 
Fig. 14 Time-longitude section at $45^{\circ} \mathrm{N}$ and time-latitude section at $25^{\circ} \mathrm{E}$ of the model simulated kinetic energy at $850 \mathrm{hPa}(\mathbf{a}, \mathbf{b})$ and $200 \mathrm{hPa}(\mathbf{c}$, d). The initial disturbance is located at $\left(20^{\circ} \mathrm{E}, 45^{\circ} \mathrm{N}\right)$. The kinetic energy field has been normalized by its maximum magnitude at each time level
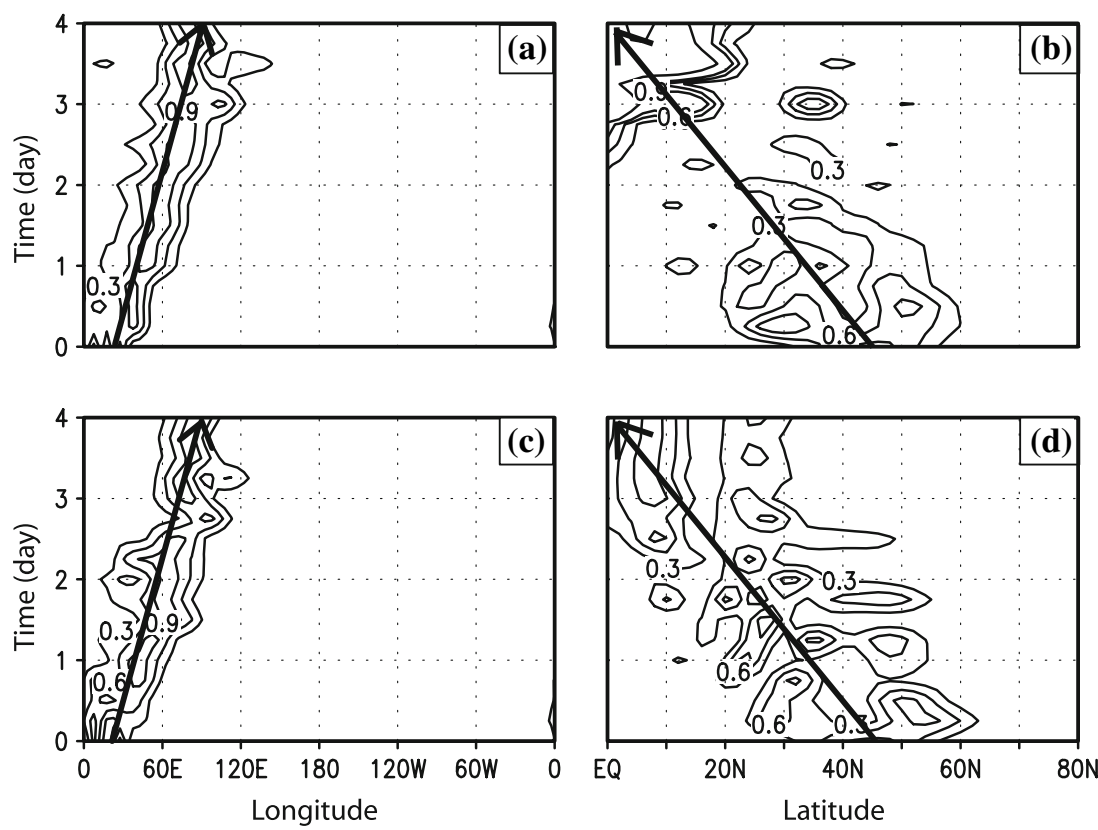

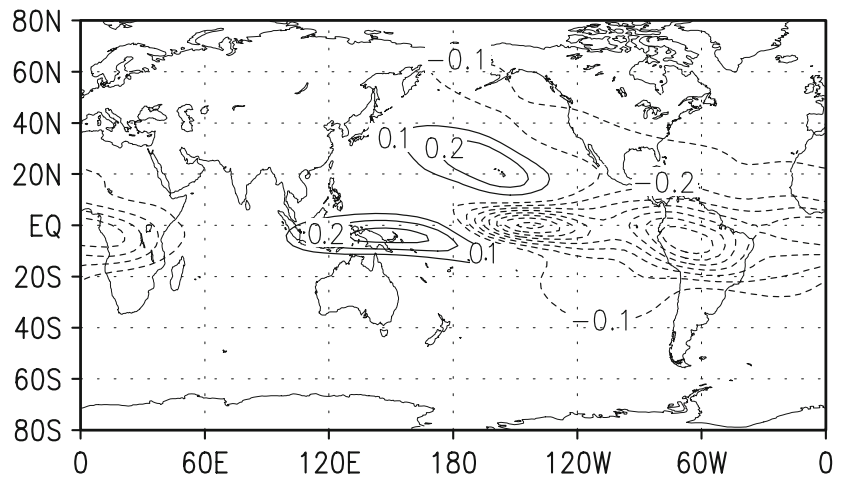

Fig. 15 Simulated $850 \mathrm{hPa}$ zonal wind field at $t=$ day 6 for the case with an initial disturbance located at $\left(180^{\circ}, 45^{\circ} \mathrm{N}\right)$

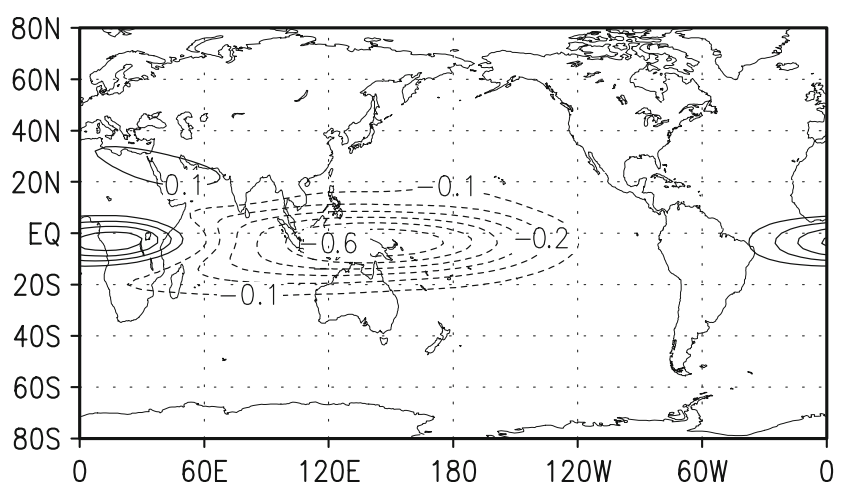

Fig. 16 As in Fig. 11f except for the specification of a zonal symmetric basic state

on the effect of the synoptic eddy feedback. A statistical closure that relates the synoptic eddy forcing to the midlatitude low-frequency flow is constructed, which leads to a new estimation of the role of the synoptic eddy feedback on the response of midlatitude low-frequency circulation to the forcing associated with tropical ISO. By applying the newly constructed statistical closure, the observed eddy feedback can be well represented in both a simple barotropic model and a 2⿺辶2-layer baroclinic model.

Our observational analysis and modeling study show that the heating associated with tropical ISO can excite a significant midlatitude response. In particular, the ISO heating in the equatorial Indian Ocean may produce a north-south dipole structure at the upper layer in the North Pacific, with an oscillation period of about 40 days. The midlatitude response has an equivalent barotropic structure while a baroclinic structure appears in the tropics. When the heating moves eastward in association with the eastward propagation of the ISO, the response pattern in the midlatitude also shifts eastward. Both the barotropic model and the $2 \frac{1}{2}$-layer model show that the strong synoptic eddy feedback appears at the Pacific and Atlantic storm track regions, in agreement with the observation. The synoptic eddy forcing has a positive feedback to the midlatitude low-frequency anomaly forced by the tropical ISO.

Our $2 \frac{1}{2}$-layer model experiments demonstrate, for the first time, the "pure" effect of the midlatitude disturbance forcing in the ISO initiation, given that the model does not contain the cloud-radiation and ocean feedbacks and preexisting global-encirculating MJOs. Given a midlatitude disturbance initially, the signal may propagate southeastward, reach the equator within several days, and trigger ISO convection at the equator. This midlatitude triggering scenario is consistent with previous (e.g., Compo et al. 1999) and current observational analysis results. The pen- 
etration of the disturbance from the midlatitude to the tropics is in the form of Rossby wave packets. Unlike a stationary Rossby wave, the southward propagation of the transient Rossby wave packets does not require the presence of westerly winds in the basic state (Hoskins and Yang 2000). Thus the midlatitude forcing may trigger a significant equatorial ISO response in both the easterly and westerly regimes.

The dynamics of the tropical-midlatitude teleconnection require a full interaction among the stationary wave, zonal mean flow, low-frequency variability, and transient wave (synoptic eddy). In the current study, we linearize the model about a time-independent basic state, so that the nonlinear feedback to the mean flow is neglected. It is desired to incorporate all interactive processes (including the nonlinearity of the system and feedbacks between dynamics and physical processes) into the models for more comprehensive studies of the tropical-midlatitude interaction.

Acknowledgments This work was supported by NSF and ONR grants N000140710145, N00014-021-0532 and N00173-06-1-G031. The International Pacific Research Center is partially sponsored by the Japan Agency for Marine-Earth Science and Technology (JAMSTEC). The authors are thankful for valuable comments from two anonymous reviewers and from Drs. Bin Wang, Shang-Ping Xie, Xiouhua Fu, and Richard Grotjahn. Thanks also go to Diane Henderson for her editorial assistance. This is SOEST contribution number 6973 and IPRC contribution number 453 .

\section{References}

Bond NA, Vecchi GA (2003) The influence of the Madden-Julian Oscillation (MJO) on precipitation in Oregon and Washington. Wea Forecasting 18:600-613

Bretherton CS, Smith C, Wallace JM (1992) An intercomparison of methods for finding coupled patterns in climate data. J Climate 5:541-560

Compo GP, Kiladis GN, Webster PJ (1999) The horizontal and vertical structure of east Asian winter monsoon pressure surges. Q J R Meteorol Soc 125:29-54

Ferranti L, Palmer TN, Molteni F, Klinker E (1990) Tropicalextratropical interaction associated with the 30-60 day oscillation. J Atmos Sci 47:2177-2199

Frederiksen JS (1983) A unified three-dimensional instability theory of the onset of blocking and cyclogenesis. Part II: Teleconnection patterns. J Atmos Sci 40:2593-2609

Frederiksen JS (2002) Genesis of intraseasonal oscillations and equatorial waves. J Atmos Sci 59:2761-2781

Frederiksen JS, Frederiksen CS (1997) Mechanisms of the formation of intraseasonal oscillations and Australian monsoon disturbances: the role of latent heat, barotropic and baroclinic instability. Contrib Atmos Phys 70:39-56

Frederksen JS, Frederiksen CS (1993) Monsoon disturbances, intraseasonal oscillations, teleconnection patterns, blocking, and storm tracks of the global atmosphere during January 1979: linear theory. J Atmos Sci 50:1349-1372

Held IM, Kang IS (1987) Barotropic models of the extratropical response to El Nino. J Atmos Sci 44:3576-3586
Held IM, Lyons SW, Nigam S (1989) Transients and the extratropical response to El Nino. J Atmos Sci 46:163-174

Hendon HH, Salby ML (1994) The life cycle of the Madden-Julian oscillation. J Atmos Sci 51:2225-2237

Higgins RW, Mo KC (1997) Persistent North Pacific circulation anomalies and the tropical intraseasonal oscillation. J Climate 10:223-244

Hoskins BJ, Karoly DJ (1981) The steady linear response of a spherical atmosphere to thermal and orographic forcing. J Atmos Sci 38:1179-1196

Hoskins BJ, Yang GY (2000) The equatorial response to higherlatitude forcing. J Atmos Sci 57:1197-1213

Hsu HH (1996) Global view of the intraseasonal oscillation during northern winter. J Climate 9:2386-2406

Hsu HH, Hoskins BJ, Jin FF (1990) The 1985/1986 intraseasonal oscillation and the role of the extratropics. J Atmos Sci 47:823839

Jin FF, Pan LL, Watanabe M (2006a) Dynamics of synoptic eddy and low-frequency flow interaction. Part I: A dynamical closure. J Atmos Sci 63:1677-1694

Jin FF, Pan LL, Watanabe M (2006b) Dynamics of synoptic eddy and low-frequency flow interaction. Part II: A theory for lowfrequency modes. J Atmos Sci 63:1695-1708

Jones C (2000) Occurrence of extreme precipitation events in California and relationships with the Madden-Julian Oscillation. J Climate 13:3576-3587

Kalnay E, Coauthors (1996) The NCEP/NCAR 40-year reanalysis project. Bull Amer Meteor Soc 77:437-471

Kiladis GN, Weickmann KM (1992) Circulation anomalies associated with tropical convection during northern winter. Mon Wea Rev 120:1900-1923

Kim BM, Lim GH, Kim KY (2006) A new look at the midlatitudeMJO teleconnection in the Northern Hemisphere winter. Quarter J Roy Soc 132:485-503

Knutson TR, Weickmann KM (1987) 30-60 atmospheric oscillation: Composite life cycles of convection and circulation anomalies. Mon Wea Rev 115:1407-1436

Kuo HL (1974) Further studies of the parameterization of the influence of cumulus convection on large-scale flow. J Atmos Sci 31:1232-1240

Lau KM, Phillips TJ (1986) Coherent fluctuations of extratropical geopotential height and tropical convection in intraseasonal time scales. J Atmos Sci 43:1164-1181

Li T, Wang B (1994) The influence of sea surface temperature on the tropical intraseasonal oscillation: a numerical study. Mon Wea Rev 122:2349-2362

Liebmann B, Hartmann DL (1984) An observational study of tropical-midlatitude interaction on intraseasonal time scales during winter. J Atmos Sci 41:3333-3350

Lim H, Chang CP (1981) A theory for midlatitude forcing of tropical motions during winter monsoons. J Atmos Sci 38:2377-2392

Lin JWB, Neelin JD, Zeng N (2000) Maintenance of tropical intraseasonal variability: impact of evaporation-wind feedback and midlatitude storms. J Atmos Sci 57:2793-2823

Madden RA (1986) Seasonal variations of the 40-50 day oscillation in the tropics. J Atmos Sci 43:3138-3158

Madden RA, Julian PR (1971) Detection of a 40-50 day oscillation in the zonal wind in the tropical Pacific. J Atmos Sci 28:702-708

Madden RA, Julian PR (1972) Description of global-scale circulation cells in the tropics with a $40-50$ day period. J Atmos Sci 29:1109-1123

Madden RA, Julian PR (1994) Observation of the 40-50 day tropical oscillation-A review. Mon Wea Rev 122:814-837

Matthews AJ (2004) Intraseasonal variability over tropical Africa during northern summer. J Climate 17:2427-2440 
Meehl GA, Kiladis GN, Weickmann KM, Wheeler M, Gutzler DS, Compo GP (1996) Modulation of equatorial subseasonal convective episodes by tropical-extratropical interaction in the Indian and Pacific Ocean regions. J Geophys Res 101:15033-15049

Navarra A (1993) A new set of orthonormal modes for linearized meteorological problems. J Atmos Sci 50:2569-2583

Nogues-Paegle J, Lee BC, Kousky VE (1989) Observed modal characteristics of the intraseasonal oscillation. J Climate 2:496507

Nogues-Paegle J, Byerle LA, Mo KC (2000) Intraseasonal modulation of South American summer precipitation. Mon Wea Rev 128:837-850

Pan LL (2003) A study of dynamic mechanisms of Annular Modes. Ph.D. dissertation, University of Hawaii, 194 pp

Pan LL, Jin FF (2005) Seasonality of synoptic eddy feedback and the AO/NAO. Geophys Res Lett 32:L21708. doi:10.1029/ 2005GL024133

Pan LL, Jin FF, Watanabe M (2006) Dynamics of synoptic eddy and low-frequency flow (SELF) interaction. Part III: Baroclinic model results. J Atmos Sci 63:1709-1725

Plumb RA (1985) On the three-dimensional propagation of stationary waves. J Atmos Sci 42:1228-1251

Schubert SD (1985) A statistical-dynamical study of empirically determined modes of atmospheric variability. J Atmos Sci 42:3-17

Schubert SD, Park CK (1991) Low-frequency intraseasonal tropicalextratropical interactions. J Atmos Sci 48:629-650

Simmons AJ, Wallace JM, Branstator GW (1983) Barotropic wave propagation and instability and atmospheric teleconnection patterns. J Atmos Sci 40:1363-1392
Straus DM, Lindzen RS (2000) Planetary-scale baroclinic instability and the MJO. J Atmos Sci 57:3609-3626

Wang B, Li T (1993) A simple tropical atmospheric model of relevance to short-term climate variation. J Atmos Sci 50:260 284

Wang B, Li T (1994) Convective interaction with boundary-layer dynamics in the development of a tropical intraseasonal system. J Atmos Sci 51:1386-1400

Wang B, Rui H (1990) Synoptic climatology of transient tropical intraseasonal convection anomalies. Meteor Atmos Phys 44:4361

Wang B, Xie X (1996) Low-frequency equatorial waves in vertically shear flow. Part I: Stable waves. J Atmos Sci 53:449-467

Weickmann KM (1983) Intraseasonal circulation and outgoing longwave radiation modes during Northern Hemisphere winter. Mon Wea Rev 111:1838-1858

Weickmann KM, Lussky GR, Kutzbach JE (1985) Intraseasonal (3060 day) fluctuations of outgoing longwave radiation and $250 \mathrm{mb}$ streamfunction during northern winter. Mon Wea Rev 113:941961

Wheeler M, Kiladis GN (1999) Convectively coupled equatorial waves: analysis of clouds and temperature in the wavenumberfrequency domain. J Atmos Sci 56:374-399

Wheeler M, Kiladis GN, Webster PJ (2000) Large-scale dynamical fields associated with convectively coupled equatorial waves. J Atmos Sci 57:613-640

Zhang C (2005) Madden-Julian oscillation. Rev Geophys 43:1-36 